\title{
Free Volume Structure and Transport Properties of Glassy Polymers-Materials for Separating Membranes
}

\author{
Vladimir V. VOLKOV \\ A. V. Topchiev Institute of Petrochemical Synthesis, \\ The USSR Academy of Sciences, \\ 117912 GSP-1, Moscow B-71, Leninsky prospect, 29, Moscow, USSR
}

(Received November 26, 1990)

\begin{abstract}
The structural organization and transport properties for various glassy polymers being utilized or having potential to be applied as the materials of separating membranes are discussed. Among them are poly(vinyltrimethylsilane)(PVTMS), poly(trimethylsilyl-1-propyne)(PTMSP), and poly(phenylene oxide) (PPO). In addition, the data for other glassy and rubbery polymers are included into consideration for the comparison. Free volume of polymers was estimated by sorption of low-molccular-wcight probe molecules at various pressures and temperatures, by positron annihilation method, by density technique including calculations by means of group contributions. Transport characteristics of polymers investigated were studied by sorption-desorption and permeation techniques. It was shown that highly permeable glassy polymers may posses free volume fraction on the level of that for highly permeable rubbers. This free volume has non-equilibrium nature and exist in the glassy polymer as a interconnected microporous network. Glassy polymers have heterogeneous structure consisting of the regions with ordered and disordered structures. The regularities of gas sorption in and transport through the glassy polymers and rubbery ones are different. The following scquence of changing in gas sorption and diffusion mechanism can be proposed: liquids, rubbery polymers, glassy polymers, highly permeable glassy polymers, microporous sorbents. sorbents.

KEY WORDS: Poly(vinyltrimethylsilane) / Poly(trimethylsilyl-1-propyne) / Positrone annihilation / Density / Sorption / Diffusion / Glassy Polymers /
\end{abstract}

Glassy polymers, in contrast to rubbery ones, for a long time were regarded to be the low permeable substances. However, the synthesis and investigation of gas permeability in poly(vinyltrimethylsilane) (PVTMS) and some of its homologs, mono-and disubstituted acetylene polymers ${ }^{2}$, and some other glassy polymers altered radically the situation. For the time being, both the less permeable polymer and the most permeable onc arc glassy polymers. These arc poly(acrylonitrilc) and poly (1-trimethylsilyl-1-propyne) (PTMSP), respectively. Range of $\mathrm{N}_{2}$ permeability constants and ideal $\mathrm{He} / \mathrm{N}_{2}$ permselectivity for glassy polymers are about 7 and 3.5 orders, respectively. Such considerable transport characteristic changes of glassy polymers could be explained by the value, nature, and structural organization of their free volume. 
It was shown earlier that the dependence of gas diffusion activation energies $E_{D}$ on glass transition temperature for the polymers has an extremal character (curve with a maximum) and $E_{D}$ varies inversely as $T_{\mathrm{g}}{ }^{3}$. It permitted

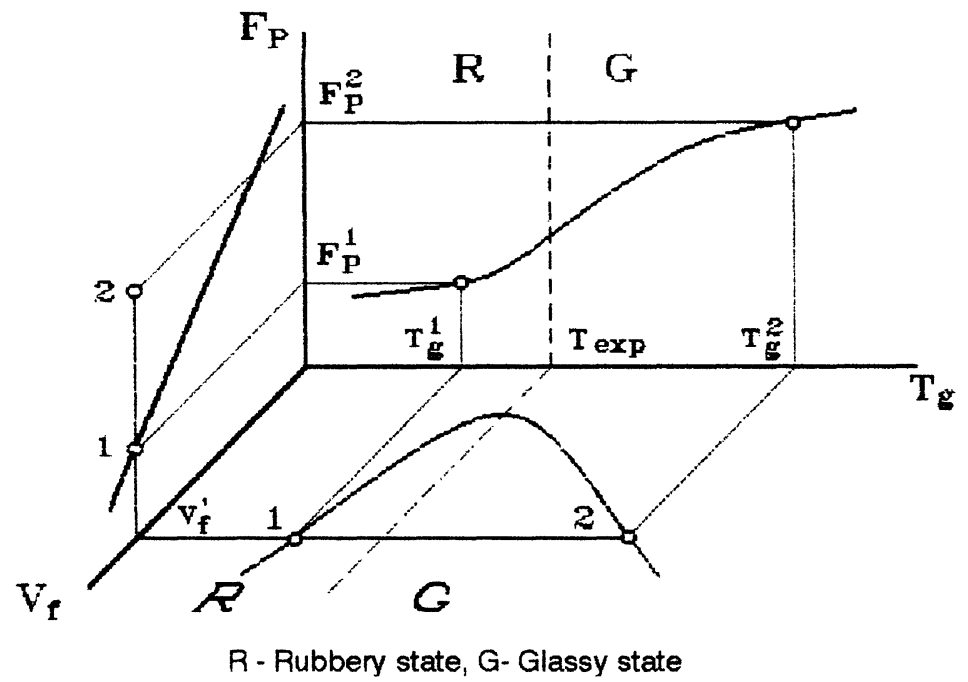

Fig. 1. Interrelation between $F_{p}, V_{f}$ and $T_{g}$ of Polymers

to suggest that the dependence on $T_{g}$ for the free volume fraction in polymer $V_{f}$, participating in the process of diffusion of light gases, has also to be described by the curve with minimum in the region of the transfer from elastic to glassy state of a polymer. The interrelation between three important for membrane gas separation parameters, namely permselectivity $F_{p}$, the fraction of free volume $V_{f}$ taking part in the diffusion of gas molecules, and glass transition temperature $T_{g}$ considered as a measure of kinetic rigidity of polymer chains is illustrated in Fig.1.

It follows from the figure that the same free volume fraction can be characteristic for two polymers (1 and 2) each one being in the different physical (rubbery and glassy) state. Therefore they are distinguished by the kinetic rigidity of polymer chains. This results in the greater valueof permselectivity for a glassy polymer having the same level of gas permeability as the rubbery one (the S-shaped dependence of gas permeability selectivity on $T_{g}$ was shown in ${ }^{4}$ ). The conclusion was done ${ }^{3}$ that glassy polymers with high values of $T_{g}$ are very prospective materials for gas separating membranes. Actually, according to the trends found, the higher the glass transition temperature of a glassy polymer is the higher value of its free volume should be. From the scientific point of view, it is of interest to investigate the origin of elevated free volume values in glassy polymers with high gas permeabilities.

Free volume of polymers was estimated by sorption and transport of low-molecular-weight probe molecules at various pressures and temperaturcs, by positron annihilation method, by density technique including calculations by means of group contributions, etc. 


\section{EXPERIMENTAL}

All polymers investigated except of PTMSP are commercial ones. 1-Trimethylsilylpropyne was obtained using Grignard reaçtion of $\mathrm{Mg}$-organic compounds from propyne and trimethylchlorsilane according to . It was polymerized in toluene solution over $\mathrm{TaCl}_{5}$ as a catalyst according to ${ }^{2}$. Monomer concentration was $1 \mathrm{M}$, that of catalyst $20 \mathrm{mmol} / \mathrm{l}$. Reaction time $-24 \mathrm{~h}$, yield of polymer $80 \%$ by weight. Molecular mass of polymer determined by gel permeation chromatography method (Waters, toluene, $50^{\circ} \mathrm{C}$ ) was shown to be: $M_{w}=590,000, M_{n}=125,000, M_{w} / M_{n}=4.72$. Intrinsic viscosity of $\mathrm{P}^{\prime}$ 'MSP was equal to $4,2(100 \mathrm{ml} / \mathrm{g})$, glass transition temperature according to DTA data obtained in vacuum is $230^{\circ} \mathrm{C}$ (Heraeus DTA-500, rate of heating 10 $\mathrm{K} / \mathrm{min}$ ).

Films of polymers were obtained by casting 1-5\% solution of polymer in appropriate solvent on cellophane surface. Gas permeability was measured by chromatographic ${ }^{6}$ and mass-spectrometric ${ }^{7}$ lechniques. Sorption in polymers was studied for pressures up to 7 atm by gravimetric ${ }^{8}$ and volumetric ${ }^{9}$ techniques. Positron life times measurcments were carricd out on the cquipment ORTEC with FWHM $=300$ ps. ${ }^{10,11}$ The radioactive isotope ${ }^{22} \mathrm{Na}$ were used as a source of positron particles.

\section{RESULTS AND DISCUSSION}

Gas molecules are often used as molecular probes for the analysis of the structure of solids. For instance, there is a well-known method of low-temperature adsorption of nitrogen vapors. Research results on gas sorption in glassy polymers in a wide range of pressures and temperatures are also quite useful for the understanding of certain aspects of the structure of these polymers and their free volume.

It is known that the sorption behavior of glassy

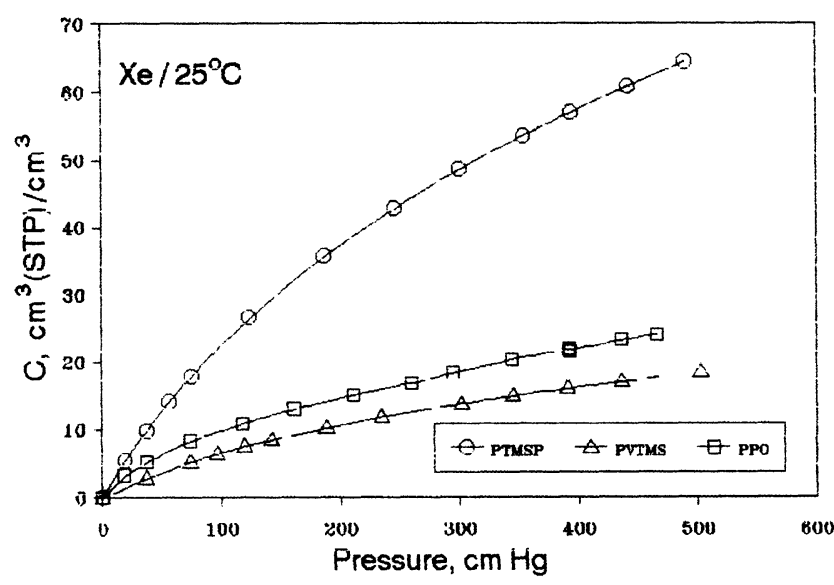

Fig. 2. Equilibrium sorption isotherms for $\mathrm{Xe}$ in PVTMS, PPO and PTMSP. polymers is different from rubbery ones. In particular, isotherms of gas sorption for glassy polymers, in contrast to rubbery oncs, have a non-lincar nature and are concave to the pressurc axis. In Fig.2 our data on Xe sorption in PVTMS, PPO, and PTMSP are presented. Such behavior can be described in the framework of the so-called dual-mode sorption model (see, for example ${ }^{12}$ ):

$$
C=C_{H}+C_{D}=k D p+C_{H}^{\prime} b p /(1+b p)
$$

where $C_{H}$ and $C_{D}$ are the concentrations of Henry's and Langmuir's populations, respectively, $k D$ is the Henry's law constant in cc(STP)/cc(polymer)*atm, $b$ is the Langmuir affinity constant in $1 / \mathrm{atm}$, and $C_{H}^{\prime}$ is the Langmuir capacity parameter in $\operatorname{cc}(\mathrm{STP}) / \mathrm{cc}$ (polymer). 
According to this model, the free volume of glassy polymers is viewed as consisting of two components: equilibrium thermal free volume, formed as a result of low-scale thermal mobility of the polymer chain fragments, and non-equilibrium unrelaxed free volume, which is present in the polymer below $T_{g}$ as "microvoids" or less densified regions. The value of $C_{H}$ is considered to be a measure of unrelaxed free volume. For example for sorption of Xe in PTMSP and PVTMS the $C_{H}^{\prime}$ values are equal to 61.7 and 18.5 , respectively. The total amount of microvoids in the glassy polymer can be also estimated by the vapour sorption and density measurements.

The density of polymers is measured by various methods which can be separated into two groups:

1. Mercury dilatometry, weighing of a sample with known geometric dimensions;

2. Gradient tube method, weighing of a sample in vacuum (or in air) and in a liquid, weighing of the picnometer with a sample immersed into the liquid, etc.

As mercury does not wet the polymer, the first set of methods gives the value of so-called "geometric" density, $\rho_{g}$ In the second set of methods the wetting liquids are used and by these techniques the so-called "picnometric" density, $\rho_{p}$, is measured. For rubbcry polymers $\rho_{g}=\rho_{p}$ but for porous substrates the valuc of $\rho_{g}$ always less than that of $\rho_{p}$ because wetting liquids fill porous structure. From this point of view, the value of $\rho_{g}$ allows to estimate the total density of microporous substrate and that of $\rho_{p}$ - the density of its dense regions. The difference between these two densities is used for estimating of total porosity of microporous polymeric sorbents ${ }^{13}$, and glassy polymers as well ${ }^{14}$. The values of $\rho_{g}$ and $\rho_{p}$ for PVTMS and PTMSP are presented in Table I.

The density of the polymer can be calculated from the group contributions as well $\left(\rho_{g r}\right)$. The group contributions of four-valent Si into the mole volume of glassy and rubbery polymers can be estimated from the densities of rubbery poly(vinyl amyldimethylsilane) and poly(vinylheptyldimethylsilane), which are equal to 0.8806

Table I. Picnometric and geometric densities as well as microvoids volume fraction for PVTMS and PTMSP

\begin{tabular}{|l|rcc|}
\hline Polymer & $\begin{array}{c}\rho_{p} \\
\mathrm{~g}^{*} \mathrm{~cm}^{-3}\end{array}$ & $\begin{array}{c}\rho_{g} \\
\mathrm{~g}^{*} \mathrm{~cm}^{-3}\end{array}$ & $\frac{\rho_{p}-\rho_{\mathrm{g}}}{\rho_{\mathrm{g}}}$ \\
\hline PTMSP & 0.964 & 0.770 & 0.20 \\
PVTMS & 0.887 & 0.836 & 0.07 \\
\hline
\end{tabular}

Table II. Microvoids volume Fraction $W$ Estimated by Various Techniques for PVTMS and PTMSP

\begin{tabular}{|c|c|c|c|}
\hline \multirow[b]{2}{*}{ Polymer } & \multicolumn{3}{|c|}{$W, \%$} \\
\hline & $\begin{array}{l}\text { Density } \\
\text { Technique }\end{array}$ & $\begin{array}{l}\text { Gas Sorption } \\
\text { e Method }\end{array}$ & $\begin{array}{c}\text { Groups Contribution } \\
\text { Method }\end{array}$ \\
\hline PVTMS & 7 & $\frac{7-9}{19}$ & 6 \\
\hline PIMSI & 20 & $20-26$ & - \\
\hline
\end{tabular}




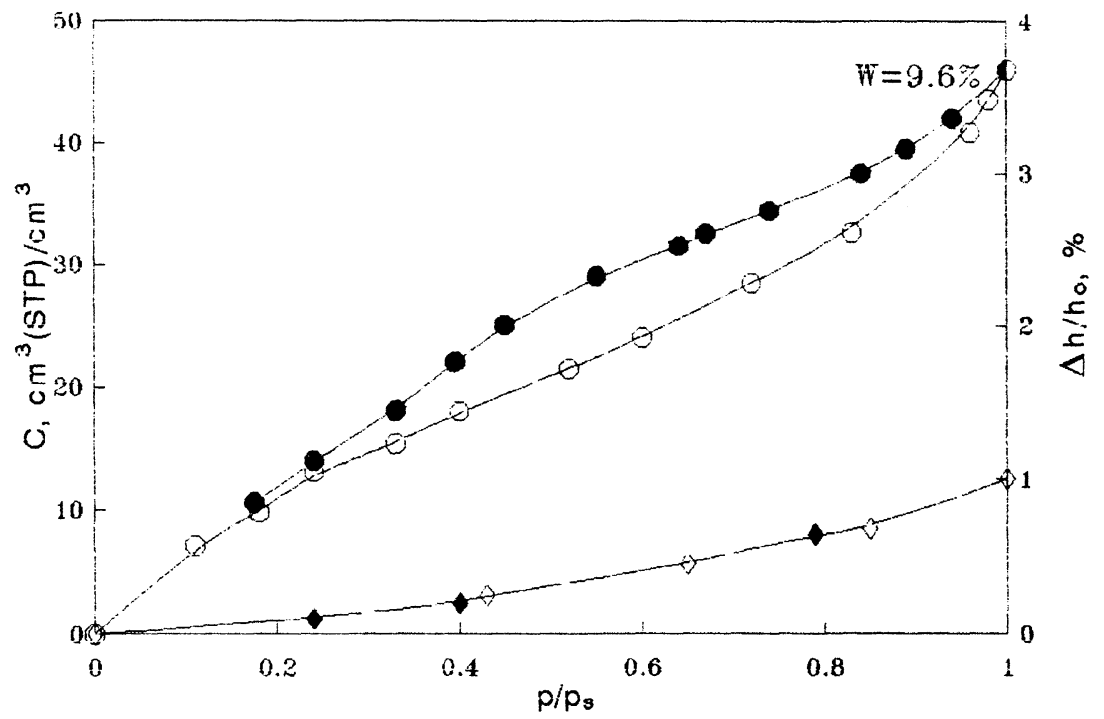

Fig. 3. Equilibrium sorption of $\mathrm{SO}_{2}$ and swelling isotherm for PVTMS at $25^{\circ} \mathrm{C}$

and 0.8764 . respectively. Using the interrelation between $V_{w}, V_{r}$ and $V_{g}$ obtained by D.W.Van Krevelen, the group contributions $V_{w}, V_{r}$ and $V_{g}$ into the mole volumes of poly(vinyltriorganosilanes) are equal to $10.38,16.60$ and 16.08 , respectively.

The total amount of microvoides in glassy polymers can be evaluated from vapour sorption isotherms measured in a whole range of relative vapour pressures. In Fig.3 the $\mathrm{SO}_{2}$ sorption-desorption isotherm and swelling for PVTMS are presented. It can be seen from the figure, the sorption-desorption hysteresis is observed for PVTMS/SO2 system. First, this may be associated with the non-equilibrium nature of the glassy polymer but the swelling sorption isotherm and desorption one are

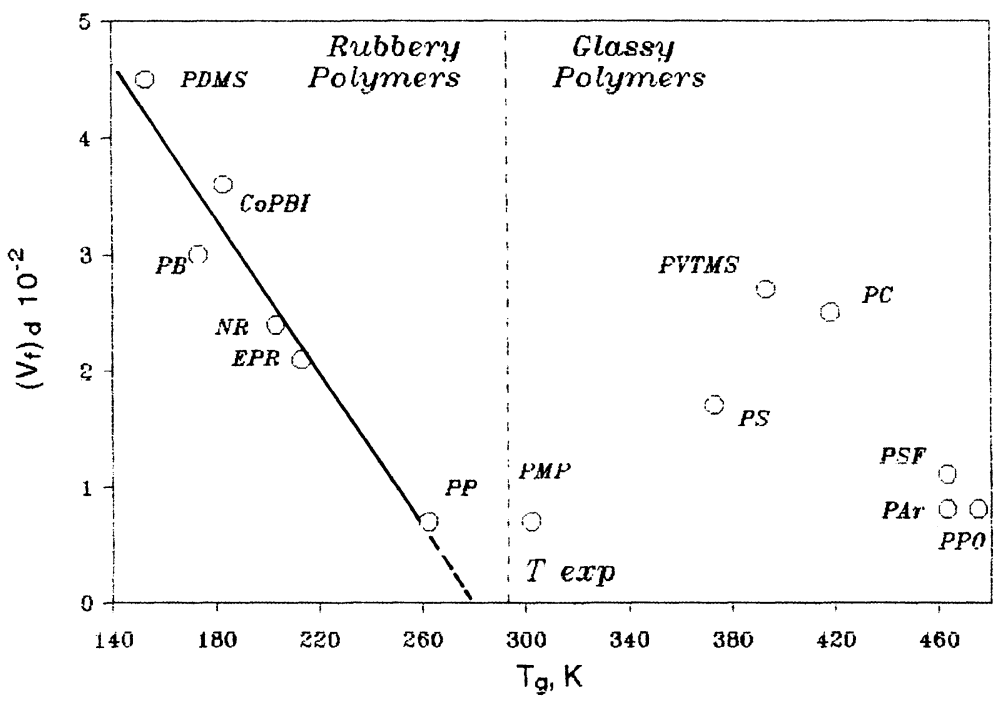

Fig. 4. Free volume fraction estimated from positron annihilation data versus glass transition temperature. 
coincide. Second, this phenomenon can be related to the existence of microporosity in PVTMS. The evaluation of the total microporosity value by the maximum amount of $\mathrm{SO}_{2}$ sorbed at $p / p_{s}=1$ gives a value of $9.6 \%\left(\rho_{L}\right.$ for $\mathrm{SO}_{2}$ at $25^{\circ} \mathrm{C}$ equal to $1.365 \mathrm{~g} / \mathrm{cc}$ ${ }^{15}$ ). Remembering the swelling of PVTMS, this value should be considered as the upper limit of microporosity in this polymer since part of $\mathrm{SO}_{2}$ sorbed should be found in the thermal free volume. Methanol vapour sorption measurements gives the value of microporosity in PVTMS equal to $6.8 \%$.. The microvoids values estimated by various methods for PVTMS and PTMSP are presented in Table II.

Analysis of $\mathrm{SO}_{2}$ isosteric sorption heats for PVTMS points to the fact that at high values of relative vapor pressures the value $\Delta H_{I}$ becomes equal to the heat of $\mathrm{SO}_{2}$ condensation. It can indicate that the processes, which are similar to polymolecular adsorption, can take place in microvoids of PVTMS. In other words, this is an indircet cvidence that in glassy PVTMS there cxist "cavitics"cach of them having volume equal to about $300 \AA^{3}$. The last estimation is consistent with the results on the rotational mobility of nitroxyl radicals substantially different in their sizes ${ }^{16}$. Depending on the ratio of the sizes of a probe and free volume element the behavior of the probe will be different. It was shown ${ }^{16}$ that for the radical TEMPO (tetramethylpyperidine xyl) rotation is free $\left(\nu=10^{9} s^{-1}\right.$ at 293 $\mathrm{K})$ in PVTMS. Meanwhile, for bicyclic nitroxyl probe drastic (by an order of magnitude) decrease in mobility $\nu_{C}$ is observed.

Another interesting method for the free volume and polymer structure analysis is the positron annihilation (PA) technique (PA spectroscopy). This method permits to follow processes separately taking place in the regions with higher and lower ordering. From this point of view it yields certain information about the microstructural properties of free volume (for instance, the sizes of free-volume "holes") and the glassy state. In the positron annihilation method it is possible to distinguish free volume ele-

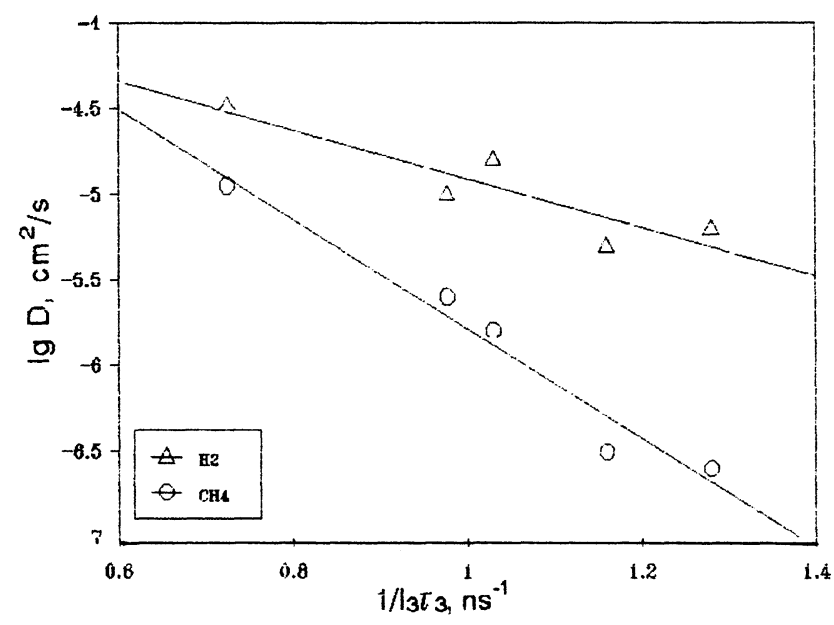

Fig. 5. Correlation of diffusion coefficients for $\mathrm{H}_{2}$ and $\mathrm{CH}_{4}$ in rubbery polymers with reciprocal of $I_{3} \tau_{3}$ (Positron annihilation data)

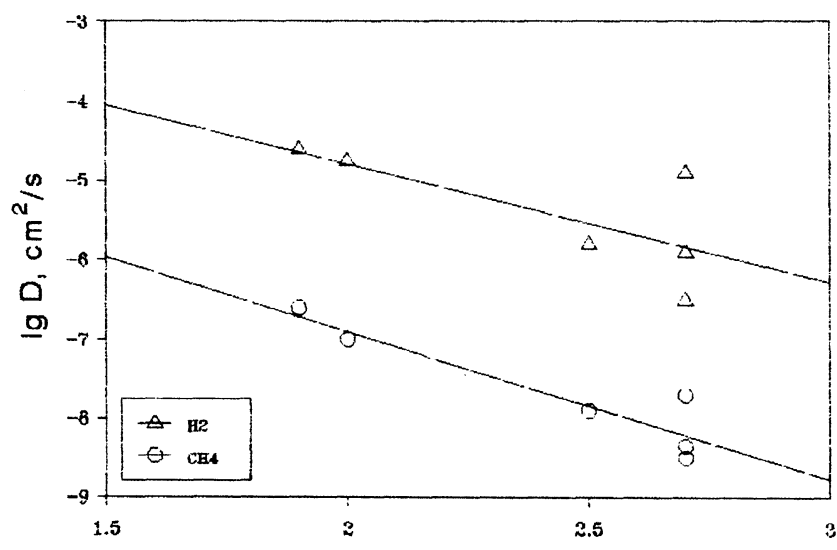

Fig. 6. Diffusion coefficients of $\mathrm{H}_{2}$ and $\mathrm{CH}_{4}$ versus $\lambda_{\text {f }}$ parameter for glassy polymers 
ments with larger and smaller sizes attributed to disordered and ordered regions, respectively, and to estimate the free volume $V_{f}$ of a polymer. $^{10,11,18}$

Using this method a number of polymers (rubbers and glasses) with glass transition temperatures $T_{g}$ in the range of $153-475 \mathrm{~K}$ was investigated. ${ }^{10,11}$ Clear corrclation is obscrved bctween $V_{f}$ and $T_{g}$ in the rubbery region (Fig.4). The $V_{g}$ values in this region monotonously decrease with $T_{g}$ approaching zero when $T_{g}=T_{\text {exp. }}$. This suggests that free volume recorded in positron annihilation (PA) method above $T_{g}$ is related mainly to the segmental mobility.

As it is seen from Fig. 5 and 6 , the gas diffusion in rubbery and glassy polymers correlates with different parameters obtained in $P \Lambda$ method. The value $\tau_{3} I_{3}$ reflects the free volume fraction in polymer (where $\tau_{3}$ is the o-positronium life time and $I_{3}$ is the intensity of this component in the spectrum). There is a linear correlation between $\tau_{3} I_{3}$ and $V_{f}{ }^{11}$ As it is seen from Fig.5, the kind of correlation between $D$ and $\tau_{3} I_{3}$ corresponds to the free volume theory predictions.

Gas diffusion cocfficients decrease with annihilation rate $\lambda_{f}$ for glassy polymers (Fig.6). Since $\lambda_{f}$ is considered as the measure of average effective electron density in the polymer the dependence of $D$ on $\lambda_{f}$ can be suggested to reflect the sensitivity of the diffusion rate to heights of potential barriers while moving along vacancy capillary formed by the elements of free volume. It should be noted that there is no similar correlation for rubbers.

Different correlations are also observed for $\mathrm{CO}_{2}$ sorption in rubbery and glassy polymers (Fig. 7 and 8). According to the Reiss's theory

$$
A^{*} \log (1 / \sigma)=B+4{ }^{*} r^{2} \gamma_{o}
$$


where $A$ is the constant for the given liquid, $B$ is the contribution associated with compression of surrounding molecules of the solvent during formation of cavity with a radius $r$ for the sorbate accommodation, $4 \pi r^{2} \gamma_{0}$ is the surface tension energy. From this it follows that there is a linear dependence between $\log (1 / \sigma)$ and $\gamma_{0}(A$ and $B$ have positive values). On the other hand. it is known that the value $1 / \tau_{3}$ is proportional to the polymer critical surface tension for a number of polymers both in rubbery and glassy states. ${ }^{18}$ Hence, $\log (1 / \sigma)$ must linearly increase with the growth of $1 / \tau_{3}$. Such a dependence is fulfilled for rubbery polymers (see Fig.7). The linear correlation between $\sigma$ and $I_{2} /\left(1-I_{2}\right)$ is observed for glassy polymers (Fig, 8). The value of $I_{2} /\left(1-I_{2}\right)$ is proportional to the overall concentration of traps of electrons and positrons. This indicates that such type of traps are responsible for the equilibrium gas sorption in glassy polymers as well.

According to the PA data (Fig.4), for some of the glassy polymers studicd (c.g. PVTMS) free volume values are the same as in rubbers (PB, natural rubber, etc.) which agrees with the extremal character of the dependence between $V_{f}$ and $T_{\xi}$ presented in Fig. 1. Meanwhile, no unified correlation of $V_{f}$ with $T_{g}$ was found for glassy polymers.

A comparison of the PA data and gas sorption and diffusion measurements indicates that probes of different physical nature are sensitive to the same structural and dynamic specific features of the polymer. However, more simple regularities (similar to the regularities observed for liquids) have been found for rubbery polymers in contrast to glassy ones.

In Table III the diffusion activation energies of light gases and hydrocarbons for PVTMS ${ }^{14,21}$ and $100 \%$ amorphous PE (calculated from the data of ${ }^{22}$ ), as well as the values of the cohesive energy densities for these two polymers, are presented. Although the values of $C E D$ are very close for the polymers considered, the $E D$ values are significant lower for PVTWS than those for PE.

Table III. Diffusion activation energy of light gases and hydrocarbons for PVTMS and PE

\begin{tabular}{|c|c|ccccccccc|}
\hline Polymer & CED & \multicolumn{10}{|c|}{ ED,Kcal/mol } \\
\cline { 3 - 10 } & $\mathrm{cal}^{\prime} \mathrm{cm}^{3}$ & $\mathrm{He}$ & $\mathrm{Ar}$ & $\mathrm{O}_{2}$ & $\mathrm{~N}_{2}$ & $\mathrm{CH}_{4}$ & $\mathrm{C}_{2} \mathrm{H}_{6}$ & $\mathrm{C}_{3} \mathrm{H}_{4}$ & $\mathrm{C}_{3} \mathrm{H}_{6}$ & $\mathrm{C}_{3} \mathrm{H}_{8}$ \\
\hline PVTMS & 67 & 2.8 & 4.2 & 4.3 & 4.4 & 5.7 & 6.0 & 6.2 & 9.0 & 10.2 \\
$\mathrm{PE}(100 \%$ & 65 & 5.4 & 8.8 & 8.3 & 8.4 & 10.1 & 12.3 & 10.9 & 12.5 & 13.8 \\
\hline
\end{tabular}

The treatment of these data on the basis of Meares's model ${ }^{23}$ made it possible to conclude that there should be interconnected micropores in PVTMS ${ }^{24}$. The average dimension of the most narrow sections of the diffusiwon path $a$ can be calculated from the formula:

$$
E D(G P) / E D(R P)=\left(d^{2}-a^{2}\right) / d^{2}
$$

where $E_{D}(G P)$ and $E_{D}(R P)$ are the gas diffusion activation energies for glassy polymer and rubbery one having the CED equal to the value of CED for the glassy polymer, $d^{2}$ is the cross section of gas molecule and $a^{2}$ is the cross section of the most narrow section of the micropore. The values of a calculated are presented in Table IV. From this it follows that the mean value of $a$ is equal to $2.6 \AA$ for PVTMS. The 
Table IV. Cross section of the most narrow part of interconnecting micropores for PVTMS.

\begin{tabular}{|c|ccccccccc|}
\hline $\mathrm{Gas}$ & $\mathrm{He}$ & $\mathrm{Ar}$ & $\mathrm{O}_{2}$ & $\mathrm{~N}_{2}$ & $\mathrm{CH}_{4}$ & $\mathrm{C}_{2} \mathrm{H}_{6}$ & $\mathrm{C}_{3} \mathrm{H}_{4}$ & $\mathrm{C}_{3} \mathrm{H}_{6}$ & $\mathrm{C}_{3} \mathrm{H}_{8}$ \\
\hline $\mathrm{a}^{2}, \mathrm{~A}^{2}$ & 3.2 & 6.1 & 5.8 & 6.5 & 6.4 & 10.1 & 7.8 & 7.0 & 6.9 \\
\hline
\end{tabular}

same approach allowed Auvil et al to conclude ${ }^{16}$ that in PTMSP there exists pore-like, continuous diffusion paths where main chains are loosely packed with a chain-to-chain separation of at least $4 \hat{\AA}$.

It means that in highly permeable glassy polymers the chains do not have to move much in order to make room for the diffusing molecules especially in the case of simple gas molecules. This is a reason of low selectivities of separation of light gases and normal hydrocarbons for PTMSP. When the cross section of the diffusing molecule exceed the $a^{2}$ value the selectivity jumps up immediately. For example the ideal permeability selectivity for $\mathrm{i}$-buthane/n-buthane is equal to 14 for PTMSP but the selectivity equal to 1.2 is observed for $n$-buthane/n-propane pair. ${ }^{25}$ The same jump of selectivity but for t-buthyl alcohol in comparison to i-buthyl alcohol was observed for pervaporation of alcohol/water mixtures through PTMSP. ${ }^{26}$

\section{CONCLUSIONS}

The data presented in this paper show that glassy polymers have heterogeneous structure consisting of the regions with ordered and disordered structures in accordance with Yeh's model ${ }^{2 f}$. The highly permeable glassy polymers may posses free volume fraction on the level of that for highly permeable rubbers. This free volume has non-equilibrium nature and exist in the glassy polymer as a interconnected microporous network. The regularities of gas sorption in and transport through the glassy polymers and rubbery ones are different. The following sequence of changing in gas sorption and diffusion mechanism can be proposed: liquids, rubbery polymers, glassy polymers, highly permeable glassy polymers, microporous sorbents.

\section{REFERENCES}

1. N.S.Nametkin, V.S.Khotimskii, S.G.Durgaryan, Dokl.AN SSSR, 166, 1118 (1966).

2. T.Masuda, T'Higashimura, Acc. Chem., Kes., 17, 51 (1984).

3. V.V.Volkov, S.G.Durgaryan, Vysokomol.Soed., A25,30 (1983).

4. V.V.Volkov, N.S.Nametkin, E.G.Novitskii, S.G.Durgaryan, Vysokomol. Soed., A21, 920 (1979).

5. O.M.Nefedov, I.E.Dolgii, E.A. Byjigitova, Izv. AN SSSR, 2842 (1975).

6. V.V.Teplyakov, A.L.Evseenko, E.G.Novitskii, S.G.Durgaryan, Plast Massy, N5, 49 (1978).

7. Yu.P.Yampolskii, S.G.Durgaryan, E.G.Novitskii, Zavodsk.Lab., N3, $256(1980)$.

8. V.V.Volkov, A.K.Bokarev, S.G.Durgaryan, Vysokomol.Soed., A26, 1294 (1984). 
9. V.V.Volkov, S.G.Durgaryan, E.G.Novitskii, N.S.Nametkin, Dokl. AN SSSR, 232, 838 (1977).

10. V.V.Volkov, A.V.Gol'danskii, S.G.Durgaryan, V.A.Onishchuk, V.P.Shantorovich, Yu.P.Yampolskii, Vysokomol.Soed., A29, 192 (1987).

11. A.V.Gol'danskii, V.A.Onishchuk, V.P.Shantorovich, V.V.Volkov, Yu.P.Yampolskii, Khim.Fisika, 7, 616 (1988).

12. V.T.Stannett, W.J.Koros, D.R.Paul, H.K.Lonsdale, R.W.Baker, Adv.Yolym.Sci., 32, 71 (1979).

13. S.A.Reitlinger, M.V.C.ilipotkina, A.A.Tager, Vysokomol.Soed., A19, 1496 (1977).

14. V.V.Volkov, Ph.D. Thesis, TIPS AN SSSR, Moscow, 1979.

15. Gas Encyclopaedia, Elsevier/L'Air Liquide, 1976.

16. S.R.Auvil. R.Srinivassan, P.M.Burban, Prepr.of Presentation, Suzdal, USSR, p.19 (1989).

17. Yu.P.Yampol'skii, A.M.Vasserman, A.L.Kovarskii, S.G.Durgaryan, N.S.Nametkin, Dokl.AN SSSR, 249, 150 (1979).

18. A.V.Gol'danskii, V.A.Onishchuk, V.P.Shantorovich, Phys.Stat.Sol., A102, 559 (1987).

19. H.Reiss, N.L.Frisch, E.Helfand, J.L.Lehovitz, J.Chem.Phys. 32. 119 (1960).

20. S.J.Tao, Appl.Phys., 3, 7 (1974).

21. V.V.Teplyakov, S.G.Durgaryan, Vysocomol.Soed., A26, 2159 (1984).

22. A.S.Michaels, , H.B.Bixler, J.Polymer Sci., 50, 413 (1961).

23. P.Mearas, J.Amer.Chem.Soc., 76, 3415 (1954).

24. V.V.Volkov, N.S.Nametkin, E.G.Novitskii, S.G.Durgaryan, Vysokomol.Soed., A21, 927 (1979).

25. A.K.Bokarev, V.V.Volkov, N.E.Kalyuzhnyi, E.G.Litvinova, V.S.Khotimskii, Yu.P.Yampol'skii, Dokl.AN SSSR, 305, 117 (1989).

26. Y.Fujii, Y.Fusaoka, M.Aoyama, E.Imazu, H.Iwatani, Prepr. 6th Int.Symp., Tubingen, 71 (1989).

27. G.S.Y.Yeh, J.Macromol.Sci., B6, 465 (1972). 